\title{
Two-Dimensional PCA Highlights the Differentiated Antitumor and Antimicrobial Activity of Methanolic and Aqueous Extracts of Laurus nobilis L. from Different Origins
}

\author{
Maria Inês Dias, ${ }^{1,2}$ João C. M. Barreira,, ${ }^{1,2}$ Ricardo C. Calhelha,, ${ }^{1,3}$ Maria-João R. P. Queiroz, ${ }^{3}$ \\ M. Beatriz P. P. Oliveira, ${ }^{2}$ Marina Soković, ${ }^{4}$ and Isabel C. F. R. Ferreira ${ }^{1}$ \\ ${ }^{1}$ Mountain Research Center (CIMO), ESA, Polytechnic Institute of Bragança, Campus de Santa Apolónia, 1172, \\ 5301-855 Bragança, Portugal \\ ${ }^{2}$ REQUIMTE, Department of Chemical Sciences, Faculty of Pharmacy of University of Porto, Rua Jorge Viterbo Ferreira, 228, \\ 4050-313 Porto, Portugal \\ ${ }^{3}$ Center of Chemistry, University of Minho, Campus de Gualtar, 4710-057 Braga, Portugal \\ ${ }^{4}$ Department of Plant Physiology, Institute for Biological Research "Siniša Stanković", University of Belgrade, \\ Bulevar Despota Stefana 142, 11000 Belgrade, Serbia
}

Correspondence should be addressed to Isabel C. F. R. Ferreira; iferreira@ipb.pt

Received 18 February 2014; Revised 24 March 2014; Accepted 27 March 2014; Published 16 April 2014

Academic Editor: Anjali Joshi

Copyright (C) 2014 Maria Inês Dias et al. This is an open access article distributed under the Creative Commons Attribution License, which permits unrestricted use, distribution, and reproduction in any medium, provided the original work is properly cited.

\begin{abstract}
Natural matrices are important sources of new antitumor and antimicrobial compounds. Species such as Laurus nobilis L. (laurel) might be used for this purpose, considering its medicinal properties. Herein, in vitro activity against human tumor cell lines, bacteria, and fungi was evaluated in enriched phenolic extracts. Specifically, methanol and aqueous extracts of wild and cultivated samples of L. nobilis were compared considering different phenolic groups. Principal component analysis (PCA) was applied to understand how each extract acts differentially against specific bacteria, fungi, and selected human tumor cell lines. In general, the extract type induced the highest differences in bioactivity of laurel samples. However, from the PCA biplot, it became clear that wild laurel samples were higher inhibitors of tumor cell lines (HeLa, MCF7, NCI-H460, and HCT15). HepG2 had the same response to laurel from wild and cultivated origin. It was also observed that methanolic extracts tended to have higher antimicrobial activity, except against $A$. niger, A. fumigatus, and P. verrucosum. The differences in bioactivity might be related to the higher phenolic contents in methanolic extracts. These results allow selecting the extract type and/or origin with highest antibacterial, antifungal, and antitumor activity.
\end{abstract}

\section{Introduction}

Laurus nobilis L. (Lauraceae), commonly known as laurel or bay leaves, is a native plant from the Southern Mediterranean region, found in warm climate regions with high rainfall [1]. It is one of the most widely used culinary spices for seasoning of meat products, soups, and fishes but is also used as an ornamental plant, especially in Europe and USA. It is also commercially grown in Turkey, Algeria, Morocco, Portugal, Spain, Italy, France, and Mexico [2-4]. The dry laurel and their infusions are traditionally used to treat gastrointestinal problems, such as epigastric, bloating, digestion, eructation, and flatulence problems. It also possesses anticonvulsive and antiepileptic activities and stimulant and narcotic properties $[2,5,6]$. The ability to suppress high blood sugar and prevent not only migraines and headaches but also bacterial and fungal infections has also been reported $[3,7]$.

Natural matrices, like $L$. nobilis, are rich sources of bioactive compounds. In fact, nearly $60 \%$ of the antitumor and anti-infectious drugs available on the market, or under clinical trial, are from natural origin $[6,8]$. The biological activities of plant extracts are well recognized, namely, their 
antifungal, antimicrobial, insecticidal, and cytostatic effects. Accordingly, the bioactivity of plant extracts is often explored in a multifactorial manner $[8,9]$.

Nowadays, there is a worldwide concern about the use of synthetic chemical compounds as antitumor agents due to their potential negative health effects, opening ways to use plants as sources of natural compounds with similar activity [10]. On the other hand, the indiscriminate use of antibiotics to treat bacterial and fungal infections led to the emergence and spread of organisms resistant to broad-spectrum antibiotics, demanding new antimicrobial agents $[11,12]$.

There are some reports on the antitumor potential of $L$. nobilis essential oil [13, 14], methanolic [15], ethanol, and aqueous extracts [8]. However, most publications regard isolated compounds $[6,16,17]$. For instance, sesquiterpene lactones and methyl esters isolated from L. nobilis leaves exhibited moderate-to-significant cytotoxicity towards K562 leukemia cells [16]. Likewise, there are a considerable number of reports on the antimicrobial effects of $L$. nobilis essential oil $[1,4,9,18-21]$, aqueous [11], ethanolic [12, 22, 23], and methanolic extracts [24]. The antimicrobial activity of $L$. nobilis is mainly related to terpenes and phenolic compounds [7, 24-26].

Despite the previous findings, and as far as we know, this is the first study exploring in vitro antimicrobial and antitumor activities from cultivated and wild L. nobilis enriched phenolic extracts. Furthermore, it was intended to compare the differentiated activity of each extract against specific bacteria, fungi, and selected human tumor cell lines, using principal component analysis.

\section{Materials and Methods}

2.1. Samples. Cultivated Laurus nobilis L. samples (leaves) were purchased from Ervital (Castro Daire, Portugal), which produces Mediterranean herbs using organic farming principles and methods. The wild samples (leaves) were collected in Bragança, Portugal, and further lyophilized (FreeZone 4.5, Labconco, KS, USA). Each sample was reduced to a fine dried powder $(20 \mathrm{mesh})$ and stored $\left(7^{\circ} \mathrm{C}\right)$ until further use.

2.2. Standards and Reagents. Fetal bovine serum (FBS), L-glutamine, Hank's balanced salt solution (HBSS), trypsinEDTA (ethylenediaminetetraacetic acid), nonessential amino acids solution $(2 \mathrm{mM})$, penicillin/streptomycin solution (100 U/mL and $100 \mathrm{mg} / \mathrm{mL}$, resp.), RPMI-1640, and DMEM media were from HyClone (Logan, UT, USA). Acetic acid, ellipticine, sulforhodamine B (SRB), trypan blue, trichloroacetic acid (TCA), and Tris were from Sigma Chemical Co. (Saint Louis, USA). Mueller-Hinton agar (MH) and malt agar (MA) were obtained from the Institute of Immunology and Virology, Torlak (Belgrade, Serbia). Dimethyl sulfoxide (DMSO) (Merck KGaA, Germany) was used as a solvent. Phosphate buffered saline (PBS) was obtained from Sigma Chemical Co. (St. Louis, USA). Methanol and all other chemicals and solvents were of analytical grade and purchased from common sources. Water was treated in a Milli-Q water purification system (TGI Pure Water Systems, USA).
2.3. Extracts Preparation. Methanolic extracts were obtained from cultivated and wild plant material. Each sample $(\approx 1 \mathrm{~g})$ was extracted by stirring with $30 \mathrm{~mL}$ of methanol, at room temperature, $150 \mathrm{rpm}$ for $1 \mathrm{~h}$. The extract was filtered through Whatman number 4 paper. The residue was then reextracted with additional $30 \mathrm{~mL}$ of methanol. The combined extracts were evaporated at $35^{\circ} \mathrm{C}$ (rotary evaporator Büchi R-210, Flawil, Switzerland) to dryness.

For aqueous extracts, plant material $(\approx 1 \mathrm{~g})$ was added to $200 \mathrm{~mL}$ of boiling distilled water, left to stand for $5 \mathrm{~min}$ out of the heating source, and then filtered under reduced pressure. The obtained extract was frozen and lyophilized.

Methanolic and aqueous extracts were redissolved in water $(8 \mathrm{mg} / \mathrm{mL})$ or $5 \%$ DMSO $(10 \mathrm{mg} / \mathrm{mL})$ for antitumor and antimicrobial activity evaluation, respectively. The final solutions were further diluted to different concentrations for bioactivity evaluation.

2.4. Antitumor Activity and Hepatotoxicity. Five human tumor cell lines were tested: MCF7 (breast adenocarcinoma), NCI-H460 (non-small cell lung cancer), HCT15 (colon carcinoma), HeLa (cervical carcinoma), and HepG2 (hepatocellular carcinoma). Cells were routinely maintained as adherent cell cultures in RPMI-1640 medium containing 10\% heatinactivated FBS and $2 \mathrm{mM}$ glutamine (MCF7, NCI-H460, and HCT15) or in DMEM supplemented with $10 \%$ FBS, $2 \mathrm{mM}$ glutamine, $100 \mathrm{U} / \mathrm{mL}$ penicillin, and $100 \mathrm{mg} / \mathrm{mL}$ streptomycin (HeLa and HepG2 cells), at $37^{\circ} \mathrm{C}$, in a humidified air incubator containing $5 \% \mathrm{CO}_{2}$. Each cell line was plated at an appropriate density $\left(7.5 \times 10^{3}\right.$ cells/well for MCF-7, NCIH460, and HCT15 or $1.0 \times 10^{4}$ cells/well for HeLa and HepG2) in 96-well plates. Sulforhodamine B assay was performed according to a procedure previously described by the authors [27]. Ellipticine was used as positive control.

For hepatotoxicity evaluation, a cell culture (PLP2) was prepared from a freshly harvested porcine liver obtained from a local slaughter house, according to an established procedure [27]. Cell culture was continued with direct monitoring every 2-3 days using a phase contrast microscope. Before confluence was reached, cells were subcultured and plated in 96-well plates at a density of $1.0 \times 10^{4}$ cells/well and cultivated in DMEM medium with $10 \% \mathrm{FBS}, 100 \mathrm{U} / \mathrm{mL}$ penicillin, and $100 \mu \mathrm{g} / \mathrm{mL}$ streptomycin. Ellipticine was used as positive control. The results were expressed in $\mathrm{GI}_{50}$ values (sample concentration that inhibited $50 \%$ of the net cell growth).

2.5. Antibacterial Activity. The following gram-positive bacteria: Staphylococcus aureus (ATCC 6538), Bacillus cereus (clinical isolate), Micrococcus flavus (ATCC 10240), and Listeria monocytogenes (NCTC 7973) and gram-negative bacteria: Escherichia coli (ATCC 35210), Pseudomonas aeruginosa (ATCC 27853), Salmonella typhimurium (ATCC 13311), and Enterobacter cloacae (ATCC 35030) were used. The microorganisms were obtained from the Mycological laboratory, Department of Plant Physiology, Institute for Biological Research "Sinisa Stanković” (IBRSS), University of Belgrade, Serbia. 
The minimum inhibitory (MIC) and minimum bactericidal (MBC) concentrations were determined by the microdilution method. Briefly, fresh overnight culture of bacteria was adjusted by the spectrophotometer to a concentration of $1 \times$ $10^{5} \mathrm{CFU} / \mathrm{mL}$. The requested $\mathrm{CFU} / \mathrm{mL}$ corresponded to a bacterial suspension determined in a spectrophotometer at $625 \mathrm{~nm}$ (OD625). Dilutions of inocula were cultured on a solid medium to verify the absence of contamination and check the validity of the inoculum. Different solvent dilutions of methanolic extract/fractions were placed in the wells containing $100 \mu \mathrm{L}$ of tryptic soy broth (TSB) and afterwards $10 \mu \mathrm{L}$ of inoculum was added. The microplates were incubated for $24 \mathrm{~h}$ at $37^{\circ} \mathrm{C}$. The MIC of each extract was detected following the addition of $40 \mu \mathrm{L}$ of iodonitrotetrazolium chloride (INT) $(0.2 \mathrm{mg} / \mathrm{mL})$ and incubation at $37^{\circ} \mathrm{C}$ for $30 \mathrm{~min}$. The lowest concentration that produced a significant inhibition (around $50 \%$ ) of the growth of the bacteria in comparison with the positive control was identified as the MIC. The minimum inhibitory concentrations (MICs) obtained from the susceptibility testing of various bacteria to tested extract/fraction were determined also by a colorimetric microbial viability assay based on reduction of INT color and compared with positive control for each bacterial strain $[28,29]$. MBC was determined by serial subcultivation of $10 \mu \mathrm{L}$ into microplates containing $100 \mu \mathrm{L}$ of TSB. The lowest concentration not showing growth after this subculturing was read as the MBC. Standard drugs, namely, streptomycin and ampicillin, were used as positive controls. DMSO (5\%) was used as negative control.

2.6. Antifungal Activity. For the antifungal bioassays, the following microfungi were used: Aspergillus fumigatus (1022), Aspergillus ochraceus (ATCC 12066), Aspergillus versicolor (ATCC 11730), Aspergillus niger (ATCC 6275), Penicillium funiculosum (ATCC 36839), Penicillium ochrochloron (ATCC 9112), Penicillium verrucosum var. cyclopium (food isolate), and Trichoderma viride (IAM 5061). The organisms were obtained from the Mycological Laboratory, Department of Plant Physiology, IBRSS, Belgrade, Serbia. The micromycetes were maintained on malt agar (MA) and the cultures were stored at $4^{\circ} \mathrm{C}$ and subcultured once a month [30].

The fungal spores were washed from the surface of agar plates with sterile $0.85 \%$ saline containing $0.1 \%$ Tween 80 $(\mathrm{v} / \mathrm{v})$. The spore suspension was adjusted with sterile saline $\left(\approx 1.0 \times 10^{3} / \mu \mathrm{L}\right.$ per well). The inocula were stored at $4^{\circ} \mathrm{C}$ for further use. Dilutions of the inocula were cultured on solid MA to verify the absence of contamination and to check the validity of the inoculum. MICs determination was performed by a serial dilution technique using 96 -well microtitre plates. The extract/fractions were dissolved in 5\% solution of DMSO and added to broth malt medium with fungal inoculum. The microplates were incubated for $72 \mathrm{~h}$ at $28^{\circ} \mathrm{C}$. The lowest concentrations without visible growth (at the binocular microscope) were defined as MIC. The minimum fungicidal concentrations (MFCs) were determined by serial subcultivation of $2 \mu \mathrm{L}$ in microtitre plates containing $100 \mu \mathrm{L}$ of malt broth per well and further incubation for $72 \mathrm{~h}$ at $28^{\circ} \mathrm{C}$. The lowest concentration with no visible growth was defined as the MFC, indicating 99.5\% killing of the original inoculum. Bifonazole and ketoconazole were used as positive controls. DMSO (5\%) was used as negative control [31].

2.7. Statistical Analysis. For wild and cultivated plant material, three samples were used and all the assays were carried out in triplicate. Data were expressed as means \pm standard deviations, maintaining the decimal places allowed by the magnitude of standard deviation.

An analysis of variance (ANOVA) with type III sums of squares was performed using the GLM (general linear model) procedure of the SPSS software. The dependent variables were analyzed using 2-way ANOVA with the factors "extract" (E) and "origin" $(\mathrm{O})$. When a statistically significant interaction $(\mathrm{E} \times \mathrm{O})$ was detected, the two factors were evaluated simultaneously by the estimated marginal means plots for the two levels of each factor. Alternatively, if no statistical significant interaction was verified, means were compared using results obtained for EB and GI that were classified using a simple $t$ test (after checking the equality of variances through Levene's test), since there were fewer than three groups.

Principal components analysis (PCA) was applied as pattern recognition unsupervised classification method. The number of dimensions to keep for data analysis was assessed by the respective eigenvalues (which should be greater than one), by Cronbach's alpha parameter (that must be positive), and also by the total percentage of variance (that should be as high as possible) explained by the number of components selected. The number of plotted dimensions was chosen in order to allow meaningful interpretations.

All statistical tests were performed at a 5\% significance level using the SPSS software, version 20.0 (SPSS Inc.).

\section{Results and Discussion}

The interactions among L. nobilis origin (cultivated or wild) and extract (methanolic or aqueous) were evaluated to verify if these factors act together to cause changes in phenolic composition and/or biological activities. Results are presented as the mean value of each origin $(\mathrm{O})$, comprising both extracts, as well as the mean value of each extract (E), containing samples from both origins. When the interaction among factors $(\mathrm{O} \times \mathrm{E})$ was significant $(P<0.05)$, acting itself as a source of variability, the comparison of means could not be performed. In these cases, the presented conclusions were drawn from the estimated marginal means (EMM) plots obtained in each case. When the interaction was not significant, a simple $t$-test (fewer than three groups) was applied to evaluate the equality of means.

3.1. Phenolic Compound Groups Present in the Studied L. nobilis Extracts. Table 1 summarizes the phenolic compound groups present inmethanolic and aqueous extracts from cultivated and wild L. nobilis, as reported in a previous study of our research group [32]. According to those results, cultivated samples showed higher concentrations of flavonols (e.g., quercetin and kaempferol derivatives) and flavones (e.g., luteolin and apigenin derivatives). On the other hand, 
TABLE 1: Phenolic compounds (mg/g) of different extracts of Laurus nobilis. The results are presented as mean \pm SD.

\begin{tabular}{ccccc}
\hline & $\begin{array}{c}\text { Total } \\
\text { flavan-3-ols }\end{array}$ & $\begin{array}{c}\text { Total } \\
\text { flavones }\end{array}$ & $\begin{array}{c}\text { Total } \\
\text { flavonols }\end{array}$ & $\begin{array}{c}\text { Total } \\
\text { phenolic }\end{array}$ \\
\hline $\begin{array}{c}\text { Origin }(\mathrm{O}) \\
\text { Cultivated }\end{array}$ & $56 \pm 8$ & $4.4 \pm 0.2$ & $26 \pm 2$ & $86 \pm 11$ \\
$\begin{array}{l}\text { Wild } \\
P \text { value } \\
(n=18)\end{array}$ & $60 \pm 4$ & $2.6 \pm 0.4$ & $7 \pm 2$ & $71 \pm 6$ \\
$\begin{array}{c}\text { Extract }(\mathrm{E}) \\
\text { Methanolic }\end{array}$ & $\mathbf{0 . 0 2 5}$ & $<\mathbf{0 . 0 0 1}$ & $<\mathbf{0 . 0 0 1}$ & $<\mathbf{0 . 0 0 1}$ \\
$\begin{array}{l}\text { Aqueous } \\
P \text { value } \\
(n=18)\end{array}$ & $52 \pm 5$ & $3 \pm 1$ & $15 \pm 9$ & $70 \pm 5$ \\
$\begin{array}{l}\text { O } \times \text { E } \\
P \text { value } \\
(n=36)\end{array}$ & $<\mathbf{0 . 0 0 1}$ & $\mathbf{0 . 1 0 4}$ & $\mathbf{0 . 2 0 7}$ & $<\mathbf{0 . 0 0 1}$ \\
\hline
\end{tabular}

The detailed phenolic profile of all laurel samples was previously described by Dias et al. [32].

methanolic extracts had the highest flavan-3-ols contents (e.g., (-)-epicatechin and a procyanidin trimer with an A-type linkage). These differences were maintained after assembling samples according to their origin or extraction type (Table 1), as previously explained. As it can be concluded, cultivated samples had higher contents in total phenolics, especially due to their higher contents in flavonols, since the amounts in flavan-3-ols were similar for both origins. All the quantified phenolic compound groups tended to be higher in methanolic extracts, probably due to the higher temperature used in aqueous extracts [33]. These tendencies were obtained from the EMM plots since the interaction among factors was significant in all cases.

3.2. Antitumor Activity of the Studied L. nobilis Extracts. The interaction among factors was again significant in all cases, except MCF7 line (Table 2). Considering each factor individually, the origin of laurel had once more higher influence, producing statistically significant differences in all cases except HepG2. Wild laurel presented lower $\mathrm{GI}_{50}$ values than cultivated samples but also higher toxicity against nontumor liver primary cells (PLP2; $114 \mu \mathrm{g} / \mathrm{mL}$ ). Nevertheless, this sample might have the potential to be used for antitumor proposes, since the $\mathrm{GI}_{50}$ values for hepatotoxicity were higher than those obtained for the tumor cell lines (except HepG2). Cultivated samples showed also antitumor activity against NCI-H460, HCT15, and HeLa, since the corresponding GI $_{50}$ values were quite lower than the toxic concentration for PLP2. Differences among aqueous and methanolic extracts were only significant for HCT15 $(47 \mu \mathrm{g} / \mathrm{mL}$ in methanolic extracts), HepG2 (144 $\mu \mathrm{g} / \mathrm{mL}$ in aqueous extracts), and PLP2 primary liver cells $(99 \mu \mathrm{g} / \mathrm{mL}$ in methanolic extracts). The results for the breast carcinoma cell line (MCF7) showed better results when compared to the essential oil of fruits and leaves of wild $L$. nobilis from Lebanon $(>400 \mu \mathrm{g} / \mathrm{mL})$ [13], but lower activity than aqueous extract from wild laurel from
Jordan against the same line $(88.32 \%$ at $50 \mu \mathrm{g} / \mathrm{mL})$ [8]. Kaileh et al. [15] only reported that the methanolic extract of wild laurel from Palestine showed no cytotoxicity.

3.3. Antibacterial Activity of the Studied L. nobilis Extracts. Extract type and origin had a significant interaction in the antibacterial activity against all species, except M. flavus (Table 3). Cultivated and wild $L$. nobilis were active against all bacteria strains with MICs of $0.04-0.12 \mathrm{mg} / \mathrm{mL}$ and $0.046-$ $0.16 \mathrm{mg} / \mathrm{mL}$, respectively. The MBCs were higher than MICs, varying from 0.09 to $0.39 \mathrm{mg} / \mathrm{mL}$ for cultivated laurel and from 0.1 to $0.29 \mathrm{mg} / \mathrm{mL}$ for wild samples. The effect of laurel origin per se was not significant for S. aureus (MIC and MBC), E. coli (MBC), and E. cloacae (MBC). Methanolic extracts were better inhibitors $(0.012-0.12 \mathrm{mg} / \mathrm{mL})$ of bacterial growth than the aqueous extracts $(0.07-0.20 \mathrm{mg} / \mathrm{mL})$, except for $M$. flavus $(P=0.858)$. In all cases, the inhibitory and bactericidal activities were higher than those obtained for the standard ampicillin. In the case of streptomycin, the inhibitory activity of the extracts was also higher, except for $S$. aureus (cultivated, wild, and aqueous samples), B. cereus (wild and aqueous samples), and L. monocytogenes (aqueous extract). The results were similar for bactericidal activity, with streptomycin showing higher activity against $S$. aureus (cultivated, wild, and aqueous samples), B. cereus (wild and aqueous samples), and L. monocytogenes (cultivated and aqueous samples). The bacterial strains more susceptible to cultivated and wild samples were E. cloacae and P. aeruginosa, respectively. On the other hand, methanolic and aqueous extractswere particularly active against $S$. aureus and $M$. flavus, respectively. Regarding MBC, the results were the same, except for aqueous extract, which proved to have highest bactericidal effect against $E$. cloacae $(0.1 \mathrm{mg} / \mathrm{mL})$.

All presented MICs were much better than those obtained by Al-Hussaini and Mahasneh [12] on the ethanolic extracts of $L$. nobilis from Jordan against $S$. aureus, B. cereus, E. coli, S. typhimurium, and P. aeruginosa. The same applies to the results obtained by El Malti and Amarouch [23] on the ethanolic extracts of laurel from Morocco against B. cereus, $S$. aureus, L. monocytogenes, E. cloacae, E. coli, and P. aeruginosa $(>2 \mathrm{mg} / \mathrm{mL})$. The inhibitory activity described herein is also higher than that reported using essential oils of laurel from Turkey (MIC values of $5 \mathrm{mg} / \mathrm{mL}$ against E. coli, S. aureus, and $P$. aeruginosa) [9]. However, better results were obtained by Adwan and Mhanna using aqueous extracts of laurel from Palestine against $S$. aureus bacterial strain $\left(<6.1 \times 10^{-3} \mathrm{mg} / \mathrm{L}\right)$, but only when conjugated with enrofloxacin and cephalexin antibiotics [11].

3.4. Antifungal Activity of the Studied L. nobilis Extracts. The interaction among factors was once more significant in almost all cases, except MIC values for $P$. ochrochloron $(P=$ $0.278)$ and $\mathrm{MBC}$ values for $A$. niger $(P=0.312)$ and $P$. ochrochloron $(P=0.052)$ (Table 4$)$. The inhibitory activity on fungal growth was more influenced by extract type, as it can be concluded from the statistically significant differences verified in all cases, except $A$. ochraceus $(P=0.077)$. Methanolic extracts were more active against A. versicolor, 
TABLE 2: Antitumor activity and hepatotoxicity $\left(\mathrm{GI}_{50}, \mu \mathrm{g} / \mathrm{mL}\right)$ of different extracts of Laurus nobilis. The results are presented as mean $\pm \mathrm{SD}^{1}$.

\begin{tabular}{|c|c|c|c|c|c|c|}
\hline & MCF7 & NCI-H460 & HCT15 & HeLa & HepG2 & PLP2-hepatotoxicity \\
\hline \multicolumn{7}{|l|}{ Origin $(\mathrm{O})$} \\
\hline Cultivated & $187 \pm 12^{\mathrm{a}}$ & $83 \pm 13$ & $56 \pm 1$ & $119 \pm 21$ & $185 \pm 7$ & $195 \pm 85$ \\
\hline Wild & $88 \pm 5^{\mathrm{b}}$ & $73 \pm 19$ & $44 \pm 7$ & $69 \pm 9$ & $166 \pm 59$ & $114 \pm 29$ \\
\hline$P$ value $(n=18)$ & $<0.001$ & 0.077 & $<0.001$ & $<0.001$ & 0.171 & $<0.001$ \\
\hline \multicolumn{7}{|l|}{ Extract $(\mathrm{E})$} \\
\hline Methanolic & $140 \pm 50$ & $74 \pm 21$ & $47 \pm 10$ & $100 \pm 41$ & $207 \pm 17$ & $99 \pm 14$ \\
\hline Aqueous & $135 \pm 53$ & $81 \pm 10$ & $53 \pm 2$ & $88 \pm 11$ & $144 \pm 37$ & $210 \pm 70$ \\
\hline$P$ value $(n=18)$ & 0.773 & 0.254 & 0.011 & 0.242 & $<0.001$ & $<0.001$ \\
\hline \multicolumn{7}{|l|}{$\mathrm{O} \times \mathrm{E}$} \\
\hline$P$ value $(n=36)$ & 0.261 & $<0.001$ & $<0.001$ & $<0.001$ & $<0.001$ & $<0.001$ \\
\hline Ellipticine & $0.91 \pm 0.04$ & $1.42 \pm 0.01$ & $1.91 \pm 0.05$ & $1.14 \pm 0.05$ & $3.2 \pm 0.5$ & $2.06 \pm 0.03$ \\
\hline
\end{tabular}

${ }^{1}$ Means within a column with different letters differ significantly $(P<0.001)$.

Trichoderma viride, P. funiculosum, and P. ochrochloron, while aqueous extracts were better in all remaining cases (except, of course, $A$. ochraceus, which gave no differences). Cultivated and wild samples gave MICs varying from 0.01 to $0.17 \mathrm{mg} / \mathrm{mL}$ and from 0.02 to $0.3 \mathrm{mg} / \mathrm{mL}$, respectively. In the cases revealing statistically significant differences, cultivated laurel samples gave higher inhibitory activity.

Concerning fungicidal activity, MFCs varied from 0.03 to $0.6 \mathrm{mg} / \mathrm{mL}$ and from 0.03 to $0.5 \mathrm{mg} / \mathrm{mL}$ for cultivated and wild samples, respectively. Both origins had the same effect on A. versicolor, A. niger, and T. viride. Comparing extract types, MFC varied from 0.016 to $0.7 \mathrm{mg} / \mathrm{mL}$ (methanolic extracts) and from 0.046 to $0.3 \mathrm{mg} / \mathrm{mL}$ (aqueous extracts). Like it was observed for inhibitory activity, the fungicidal action was more influenced by the type of extract when compared with laurel origin (except $P$. funiculosum).

For both origins and extracts, A. fumigatus (only cultivated and aqueous samples in the case of bifonazole), A. versicolor, A. ochraceus, T. viride, P. funiculosum, and $P$. ochrochloron showed better activity than bifonazole and ketoconazole. A. versicolor and $T$. viride were the most susceptible fungal strains, while $A$. niger and $P$. verrucosum showed the highest resistance. Al-Hussaini and Mahasneh [12] and Simić et al. [21] reported better results on ethanolic extracts and essential oil, respectively, of laurel leaves from Jordan and Serbia and Montenegro against $A$. niger.

3.5. Principal Component Analysis (PCA). After analysing individually each bioactivity indicator and the contents in phenolic compounds, PCA was applied to understand the true effect of either origin or extract type in a global manner. That is, instead of evaluating individual changes caused in each bioactivity indicator or phenolic compounds group, it was intended to obtain an integrated output dealing with all the effects at once. The plot of component loadings forextract type was designed with the first two dimensions (first: Cronbach's $\alpha, 0.965$; eigenvalue, 17.194; second: Cronbach's $\alpha, 0.950$; eigenvalue, 13.721), which included most variance of data (first: $40.94 \%$; second: $32.67 \%$ ). The third and fourth dimensions, despite being significant, were not plotted due to the complexity of the corresponding output. The distribution of objects (Figure 1) indicates a clear separation of methanolic and aqueous extracts (black and grey ellipses). Furthermore, objects corresponding to wild and cultivated samples were clearly separated within each type of extract. The assignment of each set of objects to either wild or cultivated samples was done according to the tabled object scores (data not shown).

Group corresponding to cultivated samples extracted with methanol (solid grey line ellipse) was characterized by the high amounts of bioactive compounds, specifically flavonols, flavones, and total phenolics, and its high bioactivity against bacteria (B. cereus, MIC and MBC, S. typhimurium, MIC and MBC, E. coli, MIC, E. cloacae, MIC, and $L$. monocytogenes, MIC) and fungi (A. ochraceus, MIC and MFC, A. versicolor, MIC, and P. funiculosum, MFC).

The most distinctive features in cultivated samples extracted with water (solid black line ellipse) were the low content in flavan-3-ols, despite having high antifungal activity against $A$. fumigatus and $A$. niger (MIC and MFC).

A third group (dashed grey line ellipse), corresponding to wild samples extracted with methanol, was characterized as having high antibacterial (S. aureus, MIC and MBC, $L$. monocytogenes, MBC, and $P$. aeruginosa, MIC), antifungal (T. viride, MIC and MFC, $P$. ochrochloron, MFC, and $P$. funiculosum, MIC), and antitumoral activities (HCT15).

The high bioactivity of wild methanolic extracts might be related to their high content in flavan-3-ols, mainly epicatechin and procyanidin trimer with an A-linkage [32], which were previously reported as having strong antibacterial activity $[34,35]$. Curiously, these extracts had an activity opposite to that demonstrated by cultivated samples extracted with water, which might indicate that the A. fumigatus and $A$. flavus are poorly susceptible to flavan-3-ols.

Similarly, wild samples extracted with water (dashed black line ellipse) had the reverse behavior in comparison to cultivated samples extracted with methanol. These aqueous extracts were mostly active against $P$. verrucosum, which seemed to have low susceptibility to favonols, flavones, and total phenolics and generally high resistance against the tested extracts (please see Section 3.4). 


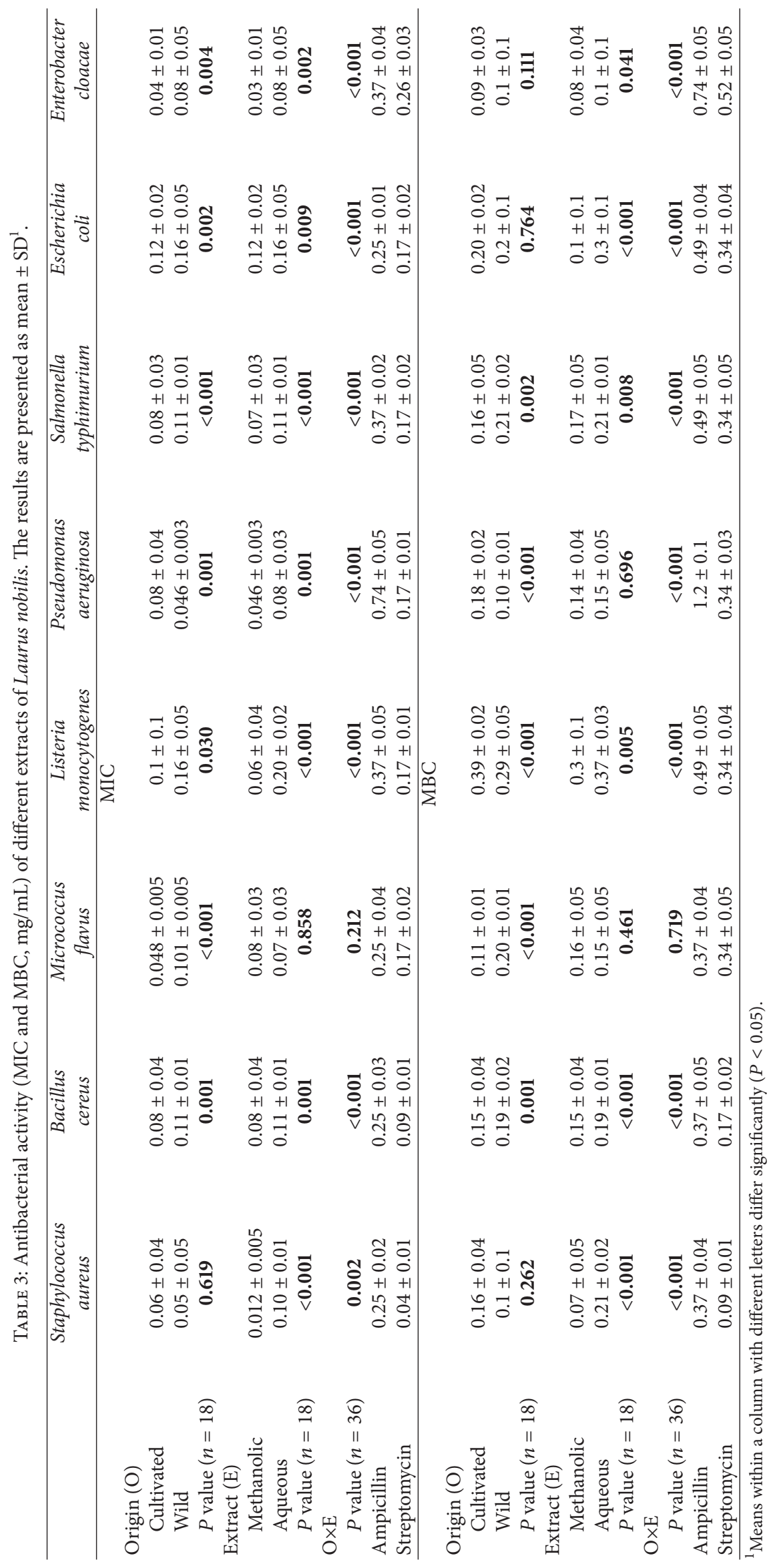




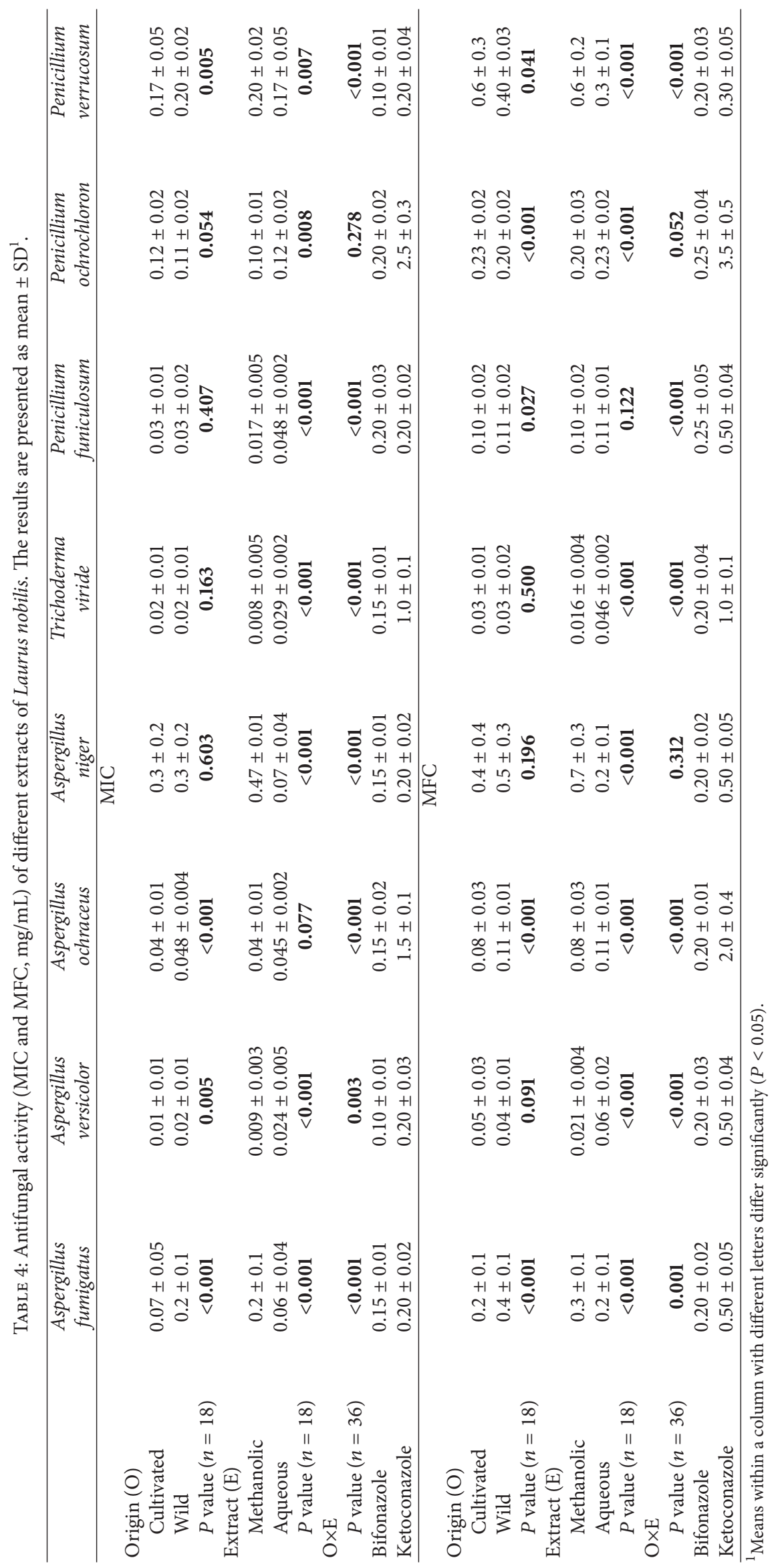




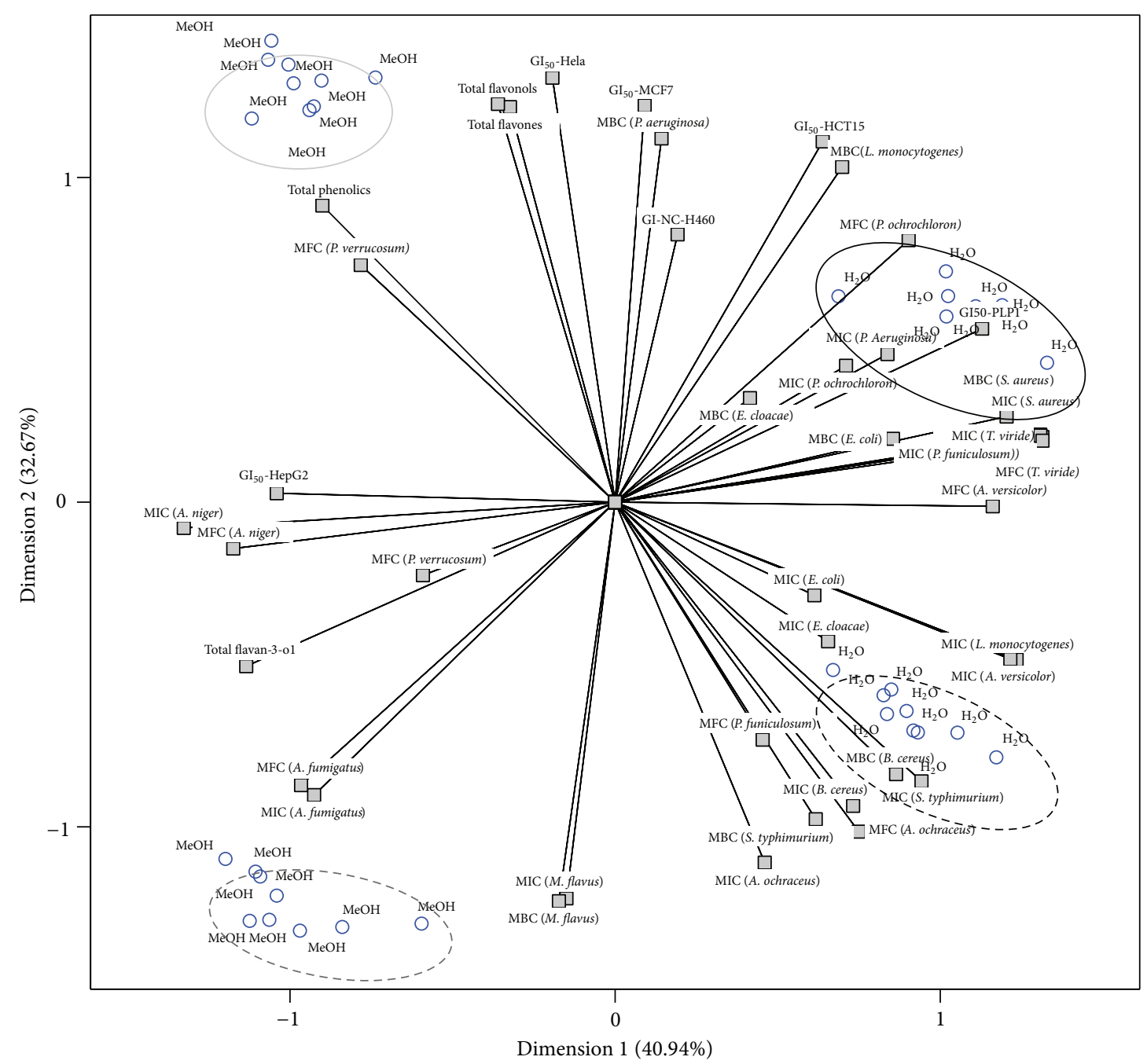

FIGURE 1: Biplot of objects (extraction solvents) and component loadings (evaluated parameters).

\section{Conclusion}

The extract type induced the most marked changes in bioactivity of laurel samples. Furthermore, each of the assayed factors (origin and extract type) acts in a differentiated manner; that is, the same evaluated parameter gave sometimes statistically significant differences regarding laurel origin, but no effect at all from extract type or vice versa. From the PCA biplot, it became clear that wild laurel samples were more effective to inhibit tumor cell lines growth, especially HeLa, MCF7, NCI-H460, and HCT15. HepG2, as previously highlighted, had the same reaction to laurel from wild and cultivated origin. It was also observed that methanolic extracts tended to have higher antimicrobial activity, except $A$. niger, A. fumigatus, and P. verrucosum. The differences in bioactivity might be related to the higher phenolic compounds contents (mainly flavan-3-ols and flavonols) presented by methanolic extracts.

The most interesting finding in this work was the bioactive specificity of each laurel extract, considering its wild or cultivated origin. In fact, from the obtained results it is possible to choose the combination extract type/origin with potentially highest effect against determined bacteria, fungi, or tumor cell line. These findings should, however, be analysed within the geographical area of study, considering eventual specific features of the used samples.

\section{Conflict of Interests}

The authors declare that they have no conflict of interests regarding the publication of this paper.

\section{Acknowledgments}

The authors are grateful to Fundacão para a Ciência e a Tecnologia (FCT, Portugal) for the financial support to CIMO (strategic project PEst-OE/AGR/UI0690/2011) and REQUIMTE (PEst-C/EQB/LA0006/2011). M. I. Dias, R. Calhelha, and J. C. M. Barreira also thank FCT, POPHQREN, and FSE for their Grants (SFRH/BD/84485/2012, SFRH/BPD/ $68344 / 2010$, and BPD/72802/2010). The authors also thank 
to Serbian Ministry of Education and Science for financial support (grant number 173032).

\section{References}

[1] H. Marzouki, A. Piras, K. B. H. Salah et al., "Essential oil composition and variability of Laurus nobilis L. growing in Tunisia, comparison and chemometric investigation of different plant organs," Natural Product Research, vol. 23, no. 4, pp. 343354, 2009.

[2] A. Barla, G. Topçu, S. Öksüz, G. Tümen, and D. G. I. Kingston, "Identification of cytotoxic sesquiterpenes from Laurus nobilis L," Food Chemistry, vol. 104, no. 4, pp. 1478-1484, 2007.

[3] F. Fang, S. Sang, K. Y. Chen, A. Gosslau, C.-T. Ho, and R. T. Rosen, "Isolation and identification of cytotoxic compounds from Bay leaf (Laurus nobilis)," Food Chemistry, vol. 93, no. 3, pp. 497-501, 2005.

[4] J. Ivanoić, D. Mišin, M. Ristić, O. Pešić, and I. Žižović, "Supercritical $\mathrm{CO}_{2}$ extract and essential oil of bay (Laurus nobilis L.) chemical composition and antibacterial activity," Journal of the Serbian Chemical Society, vol. 75, pp. 395-404, 2010.

[5] S. Dall'Acqua, R. Cervellati, E. Speroni et al., "Phytochemical composition and antioxidant activity of Laurus nobilis L. leaf infusion," Journal of Medicinal Food, vol. 12, no. 4, pp. 869-876, 2009.

[6] E. Panza, M. Tersigni, M. Iorizzi et al., "Lauroside B, a megastigmane glycoside from Laurus nobilis (bay laurel) leaves, induces apoptosis in human melanoma cell lines by inhibiting NF- $\kappa \mathrm{B}$ activation," Journal of Natural Products, vol. 74, no. 2, pp. 228 233, 2011.

[7] C. Ramos, B. Teixeira, I. Batista et al., "Antioxidant and antibacterial activity of essential oil and extracts of bay laurel Laurus nobilis Linnaeus (Lauraceae) from Portugal," Natural Product Research, vol. 26, no. 6, pp. 518-529, 2012.

[8] J. Z. Al-Kalaldeh, R. Abu-Dahab, and F. U. Afifi, "Volatile oil composition and antiproliferative activity of Laurus nobilis, Origanum syriacum, Origanum vulgare, and Salvia triloba against human breast adenocarcinoma cells," Nutrition Research, vol. 30, no. 4, pp. 271-278, 2010.

[9] I. Dadalioğlu and G. A. Evrendilek, "Chemical compositions and antibacterial effects of essential oils of Turkish oregano (Origanum minutiflorum), bay laurel (Laurus nobilis), Spanish lavender (Lavandula stoechas L.), and fennel (Foeniculum vulgare) on common foodborne pathogens," Journal of Agricultural and Food Chemistry, vol. 52, no. 26, pp. 8255-8260, 2004.

[10] M. Carocho and I. C. F. R. Ferreira, "The role of phenolic compounds in the fight against cancer-a review," Anticancer Agents in Medicinal Chemistry, vol. 13, pp. 1236-1238, 2013.

[11] G. Adwan and M. Mhanna, "Synergistic effects of plant extracts and antibiotics on Staphylococcus aureus strains isolated from clinical specimens," Middle-East Journal of Scientific Research, vol. 3, pp. 134-139, 2008.

[12] R. Al-Hussaini and A. M. Mahasneh, "Microbial growth and quorum sensing antagonist activities of herbal plants extracts," Molecules, vol. 14, no. 9, pp. 3425-3435, 2009.

[13] M. R. Loizzo, R. Tundis, F. Menichini, A. M. Saab, G. A. Statti, and F. Menichini, "Cytotoxic activity of essential oils from Labiatae and Lauraceae families against in vitro human tumor models," Anticancer Research, vol. 27, no. 5, pp. 3293-3299, 2007.

[14] A. M. Saab, R. Tundis, M. R. Loizzo et al., "Antioxidant and antiproliferative activity of Laurus nobilis L. (Lauraceae) leaves and seeds essential oils against K562 human chronic myelogenous leukaemia cells," Natural Product Research, vol. 26, pp. 1741-1745, 2012.

[15] M. Kaileh, W. V. Berghe, E. Boone, T. Essawi, and G. Haegeman, "Screening of indigenous Palestinian medicinal plants for potential anti-inflammatory and cytotoxic activity," Journal of Ethnopharmacology, vol. 113, no. 3, pp. 510-516, 2007.

[16] E. Julianti, K. H. Jang, S. Lee et al., "Sesquiterpenes from the leaves of Laurus nobilis L.," Phytochemistry, vol. 80, pp. 70-76, 2012.

[17] S. Lee, S.-C. Chung, S.-H. Lee et al., "Acylated kaempferol glycosides from Laurus nobilis leaves and their inhibitory effects on $\mathrm{Na}^{+} / \mathrm{K}^{+}$-adenosine triphosphatase," Biological and Pharmaceutical Bulletin, vol. 35, no. 3, pp. 428-432, 2012.

[18] U. de Corato, O. Maccioni, M. Trupo, and G. Di Sanzo, "Use of essential oil of Laurus nobilis obtained by means of a supercritical carbon dioxide technique against post harvest spoilage fungi," Crop Protection, vol. 29, no. 2, pp. 142-147, 2010.

[19] A. F. Millezi, D. S. Caixeta, D. F. Rossoni, M. G. Cardoso, and R. G. Piccoli, "In vitro antimicrobial properties of plant essential oils Thymus vulgaris, Cymbopogon citratus and Laurus nobilis against five important foodborne pathogens," Ciência e Tecnologia de Alimentos, vol. 32, pp. 167-172, 2012.

[20] S. Santoyo, R. Lloría, L. Jaime, E. Ibañez, F. J. Señoráns, and G. Reglero, "Supercritical fluid extraction of antioxidant and antimicrobial compounds from Laurus nobilis L. Chemical and functional characterization," European Food Research and Technology, vol. 222, no. 5-6, pp. 565-571, 2006.

[21] A. Simić, M. D. Soković, M. Ristić, S. Grujić-Jovanović, J. Vukojević, and P. D. Marin, "The chemical composition of some Lauraceae essential oils and their antifungal activities," Phytotherapy Research, vol. 18, pp. 713-717, 2004.

[22] Ö. Ertürk, "Antibacterial and antifungal activity of ethanolic extracts from eleven spice plants," Biologia, vol. 61, no. 3, pp. 275-278, 2006.

[23] J. El Malti and H. Amarouch, "Antibacterial effect, histological impact and oxidative stress studies from Laurus nobilis extract," Journal of Food Quality, vol. 32, no. 2, pp. 190-208, 2009.

[24] N. Fukuyama, C. Ino, Y. Suzuki et al., "Antimicrobial sesquiterpenoids from Laurus nobilis L," Natural Product Research, vol. 25, no. 14, pp. 1295-1303, 2011.

[25] M.-H. Liu, N. Otsuka, K. Noyori et al., "Synergistic effect of kaempferol glycosides purified from Laurus nobilis and fluoroquinolones on methicillin-resistant Staphylococcus aureus," Biological and Pharmaceutical Bulletin, vol. 32, no. 3, pp. 489492, 2009.

[26] N. Otsuka, M.-H. Liu, S. Shiota et al., "Anti-methicillin resistant Staphylococcus aureus (MRSA) compounds isolated from Laurus nobilis," Biological and Pharmaceutical Bulletin, vol. 31, no. 9, pp. 1794-1797, 2008.

[27] C. Pereira, R. C. Calhelha, L. Barros, and I. C. F. R. Ferreira, "Antioxidant properties, anti-hepatocellular carcinoma activity and hepatotoxicity of artichoke, milk thistle and borututu," Industrial Crops and Products, vol. 49, pp. 61-65, 2013.

[28] CLSI Clinical and Laboratory Standards Institute, "Methods for dilution antimicrobial susceptibility tests for bacteria that grow aerobically," Approved standard, 8th ed. CLSI publication M07-A8. Clinical and Laboratory Standards Institute, Wayne, Pa, USA, 2009.

[29] T. Tsukatani, H. Suenaga, M. Shiga et al., "Comparison of the WST- 8 colorimetric method and the CLSI broth microdilution 
method for susceptibility testing against drug-resistant bacteria," Journal of Microbiological Methods, vol. 90, pp. 160-166, 2012.

[30] C. Booth, "Fungal culture media," in Methods in Microbiology, J. R. Norris and D. W. Ribbons, Eds., pp. 49-94, Academic Press, New York, NY, USA, 19711971.

[31] A. Espinel-Ingroff, "Comparison of the E-test with the NCCLS M38-P method for antifungal susceptibility testing of common and emerging pathogenic filamentous fungi," Journal of Clinical Microbiology, vol. 39, no. 4, pp. 1360-1367, 2001.

[32] M. I. Dias, L. Barros, M. Dueñas et al., "Nutritional and antioxidant contributions of Laurus nobilis L. leaves: would be more suitable a wild or a cultivated sample?" Food Chemistry, vol. 156, pp. 339-346, 2014.

[33] C. Santos-Buelga, S. Gonzalez-Manzano, M. Dueñas, and A. M. Gonzalez-Paramas, "Extraction and isolation of phenolic compounds," Methods in Molecular Biology, vol. 864, pp. 427464, 2012.

[34] J. W. Betts, S. M. Kelly, and S. J. Haswell, "Antibacterial effects of theaflavin and synergy with epicatechin against clinical isolates of Acinetobacter baumannii and Stenotrophomonas maltophilia," International Journal of Antimicrobial Agents, vol. 38, no. 5, pp. 421-425, 2011.

[35] T. O. Idowu, A. O. Ogundaini, A. O. Salau, E. M. Obuotor, M. Bezabih, and B. M. Abegaz, "Doubly linked, A-type proanthocyanidin trimer and other constituents of Ixora coccinea leaves and their antioxidant and antibacterial properties," Phytochemistry, vol. 71, no. 17-18, pp. 2092-2098, 2010. 

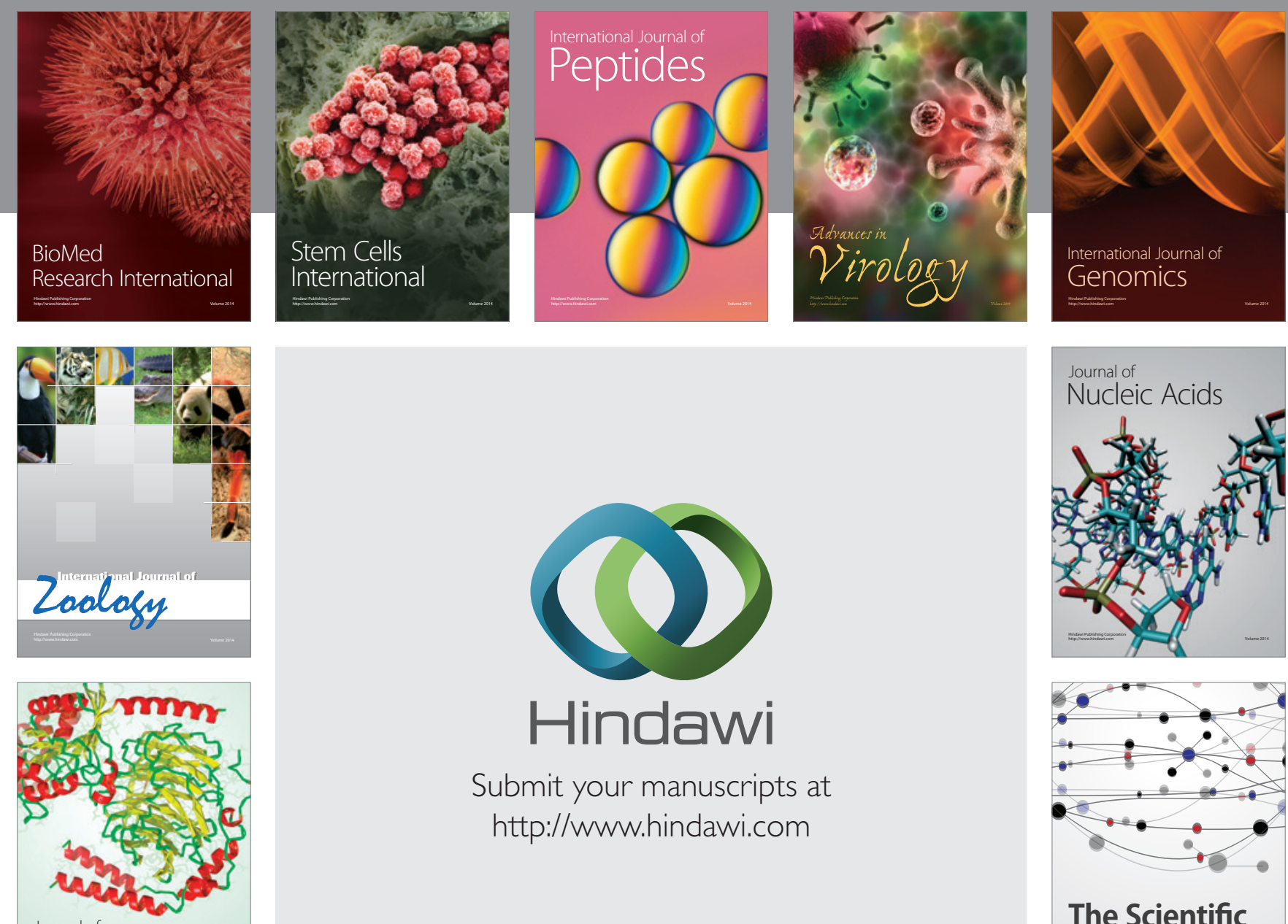

Submit your manuscripts at

http://www.hindawi.com

Journal of
Signal Transduction
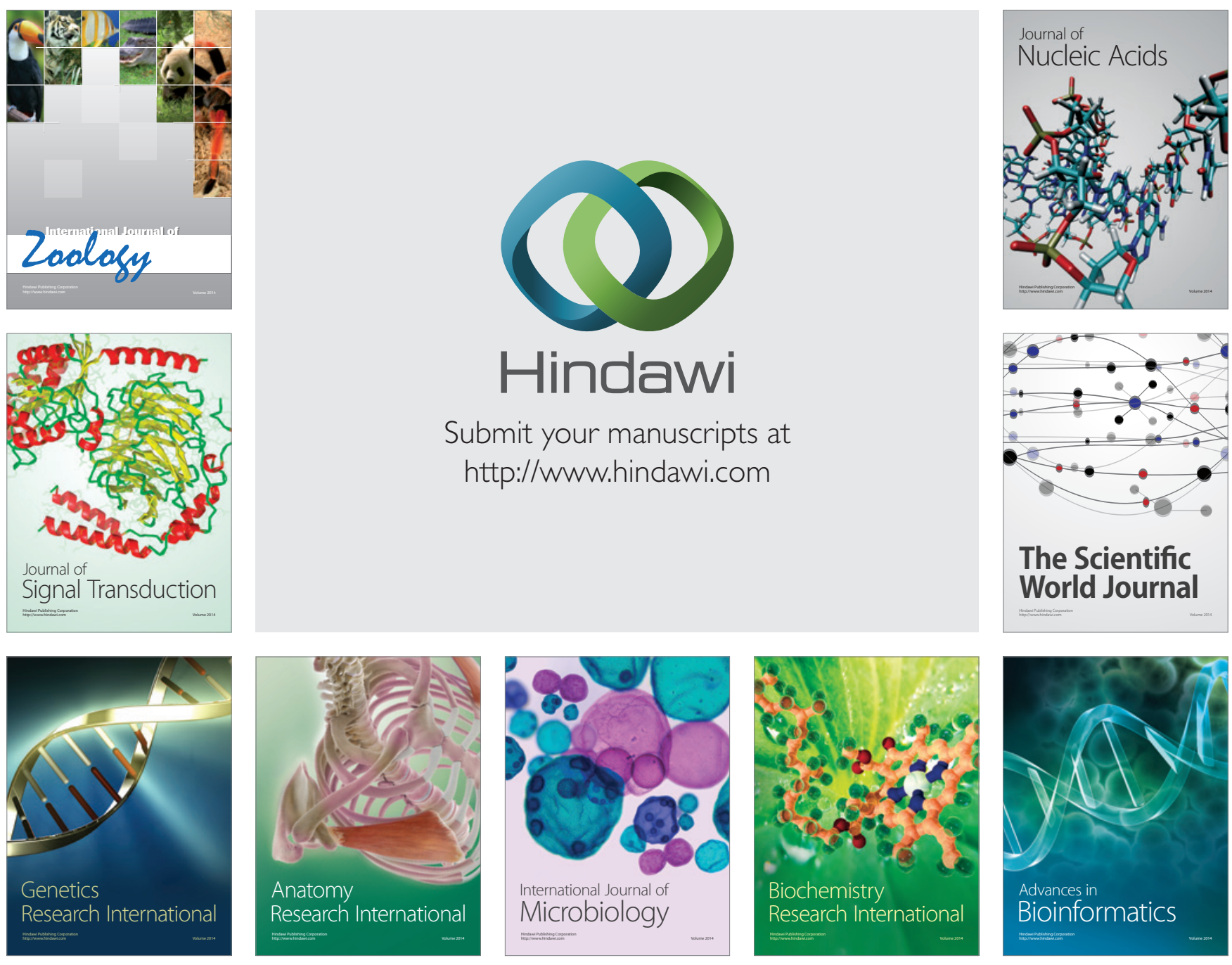

The Scientific World Journal
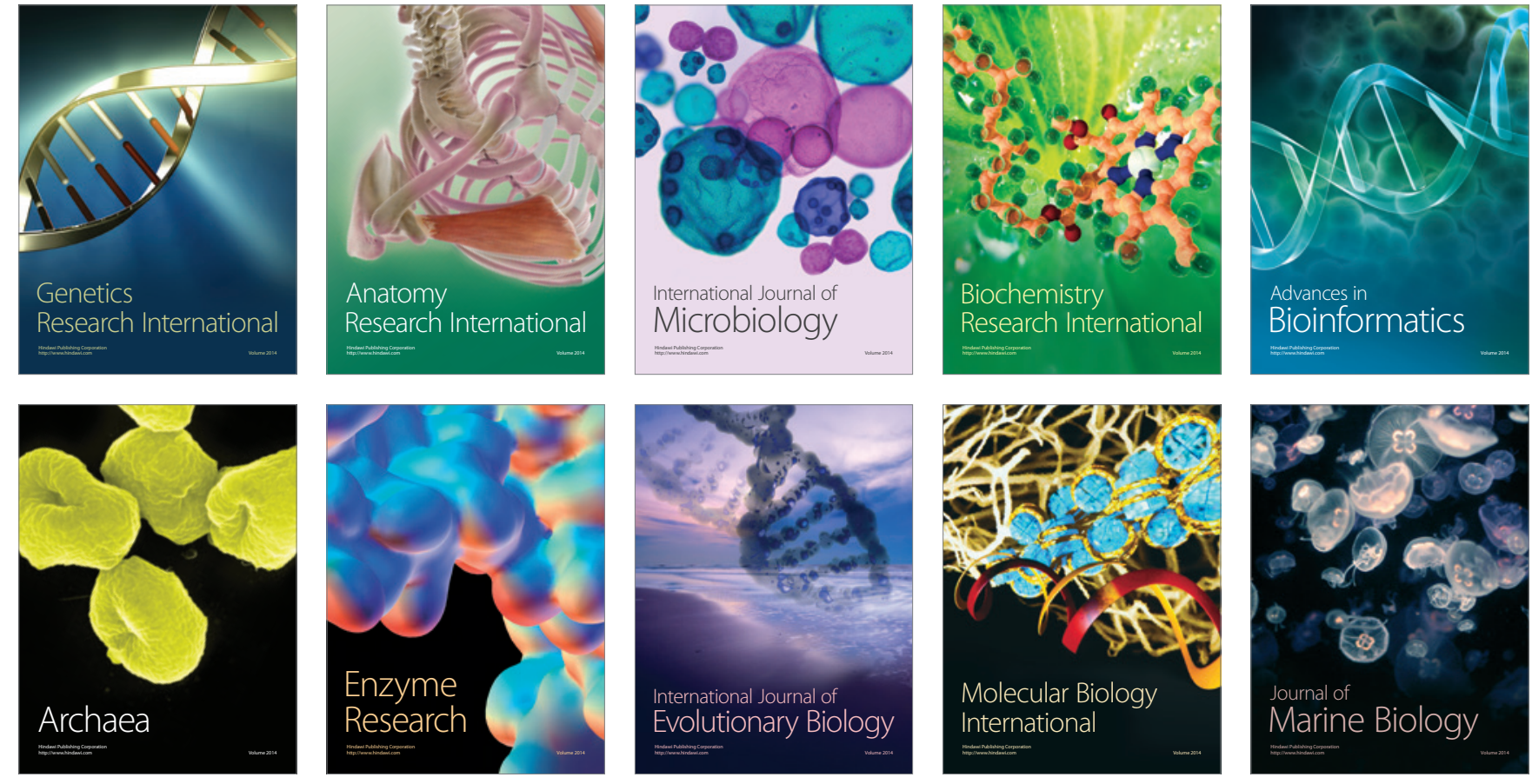